\title{
An In Silico Approach for Identification of Inhibitors as a Potential Therapeutics Targeting SARS-Cov-2 Protease
}

\author{
Estari Mamidala*, Rakesh Davella and Swapna Gurrapu \\ Infectious Diseases Research Lab, Department of Zoology, Kakatiya University, Hanamkonda, Warangal \\ -506009, Telangana, India; drestari@kakatiya.ac.in
}

\begin{abstract}
SARS-CoV-2 caused COVID-19 which is pandemic and is a global health emergency. Protease is the drug target for corona viruses and this enzyme processes the production of polyproteins from the viral RNA. Objective of this study is to find the inhibitors against SARS-Cov-2 protease. AutoDock 4.2 was used for docking calculations. To check different molecules, test ligands like lopinavir, ritonavir (retroviral drugs) and hydroxychloroquine (anti-malarial drug) were docked against our target enzyme protease retrieved from Protein Data Bank. With respect to docking free binding energy, it is revealed that, Hydroxychloroquine has the lowest binding energy followed by Ritonavir and Lopinavir binds significantly to target enzyme protease. The results of this study provide a solid base for the use of Hydroxychloroquine against COVID-19 treatment. The interactions from structural models at the protease active site of virus can offer a valuable guide for more strategies for structure-based medications and the development of more operative inhibitors of SARS-CoV-2 protease.
\end{abstract}

Keywords: COVID-19, Hydroxychloroquine, In Silico, Lopinavir, Ritonavir, SARS-Cov-2iProtease

\section{Introduction}

The outbreak of COVID-19 is caused by severe acute respiratory syndrome coronavirus-2 (SARS-CoV-i2) appears to have happening in Wuhan, China in December $2019^{1,2}$. Afterward, it has extent within and outside China ${ }^{3,4}$ and has develop an unparalleled global communal health issue ${ }^{5}$. As of $23^{\text {rd }}$ March 2020, India has 471 confirmed cases of Covid-19, including nine deaths ${ }^{6}$. According to data from the Indian Council of Medical Research a total of 20,864 samples from 19,974 individuals have been tested for SARS-CoV2 as on $24^{\text {th }}$ March 2020. A total of 482 individuals have been confirmed positive among suspected cases and contacts of known positive cases $^{7}$. Thirty states and union territories in India have announced a complete lockdown to curb the spread of corona virus.

One of the best considered drug targets of corona viruses is the main protease ${ }^{8}$. Beside with the papainlike protease(s), this enzyme is important for producing the polyproteins that are translated from the viral RNA. Constraining the activity of this enzyme would block viral duplication. Meanwhile no human proteases with similar cleavage specificity are recognized, inhibitors are improbable to be lethal. Currently, there is no exact treatment beside the new virus. Thus, finding active antiviral mediators to combat the infection is immediately desirable. An effective attitude to drug discovery is to check whether the existing antiviral medicines are operative in treating linked with viral infections. Computational approaches are dynamic part

${ }^{*}$ Author for correspondence 
of the medicine scheme procedure and they are presently used to acquire a deep considerate into the ligand-receptor/ protein interfaces. In this current study, we evaluated the antiviral efficiency of FDA approved two retroviral drugs (Lopinavir, ritonavir) and one well-known broad-spectrum anti-malarial drug (Hydroxychloroquine) against a novel SARS-CoV-2 protease (COVID-19) or In Silico.

\section{Materials and Methods}

\subsection{PASS Prediction}

For activity spectra prediction of the considered drugs the program PASS was required. PASS, calculates the natural efficacy spectrum of a molecule built on the examination of structural performance associations of above one million of recognizedmolecules ${ }^{9}$. These molecules possess over 80 different biological actions. The normal exactness of prediction is nearby $95 \%$.

\subsection{Molecular Docking Methods}

For molecular docking, Auto-Dock 4.2 software was used $^{10}$. The free energy (DG) binding of SARS-CoV-2 viral protease with the selected compounds was created by means of this molecular docking package.

Docking is a computational simulation method of a ligand binding to a receptor or enzyme and expects the favored orientation of binding of one molecule to the $2^{\text {nd }}$ to form a steady complex. To predict the attraction and activity of binding of the minor molecule to their enzyme targets by using scoring functions docking is used. Therefore, docking shows significant role in the rational design of medicines. The sensitivity of docking calculations concerning the geometry of the involvement ligand displays that even minor changes in the ligand structure can lead to big changes in the geometries and scores of the subsequent docked poses.

\subsubsection{Selection of Ligand}

Anti-viral and anti-malarial medications were recognized as potential corona virus inhibitors from diverse literature evaluations. The three-dimensional structure files of the selected compounds were downloaded in SDF format from the PubChem 3-D was used for molecular docking. Figures $1(\mathbf{a}, \mathbf{b}, \mathbf{\&} \mathbf{c})$ show the structures of selected different ligands.

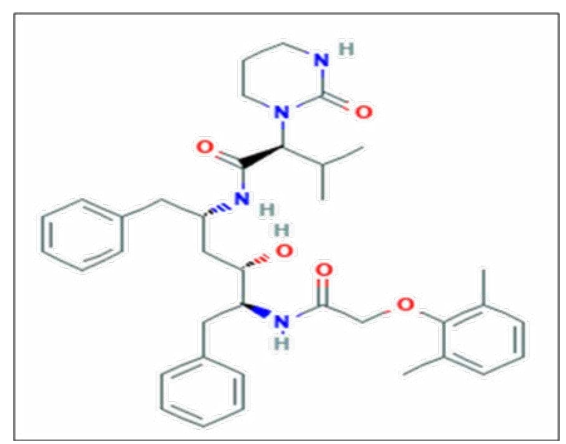

(a)

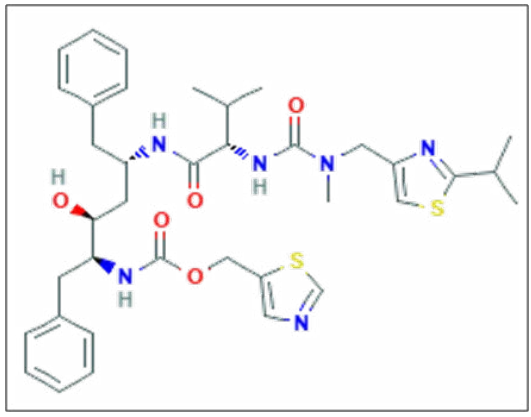

(b)

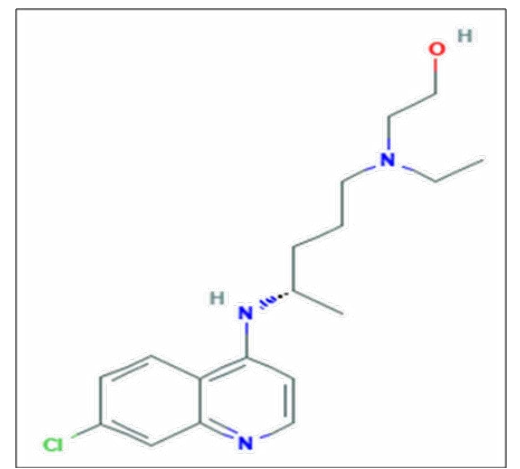

(c)

Figure 1. Test ligands (a-c): (a): Lopinavir, (b): Ritonavir, (c): Hydroxychloroquine.

\subsubsection{Selection of Target}

The main COVID-19 protease remained used as a target to novelty repurposing candidates over computational selection amongst clinically accepted drugs. The study identified a list of FDA permitted two retroviral drugs and one anti-malarial medicine that may form hydrogen bonds to key residues of amino acids within the binding pocket of viralprotease and may too have a higher tolerance to conflict mutations. The crystal 3D structure of SARS-CoV-i2 protease (PDB ID: 6LU7) remained obtained from Protein-Data Bank ${ }^{11}$ (Figure 2). 


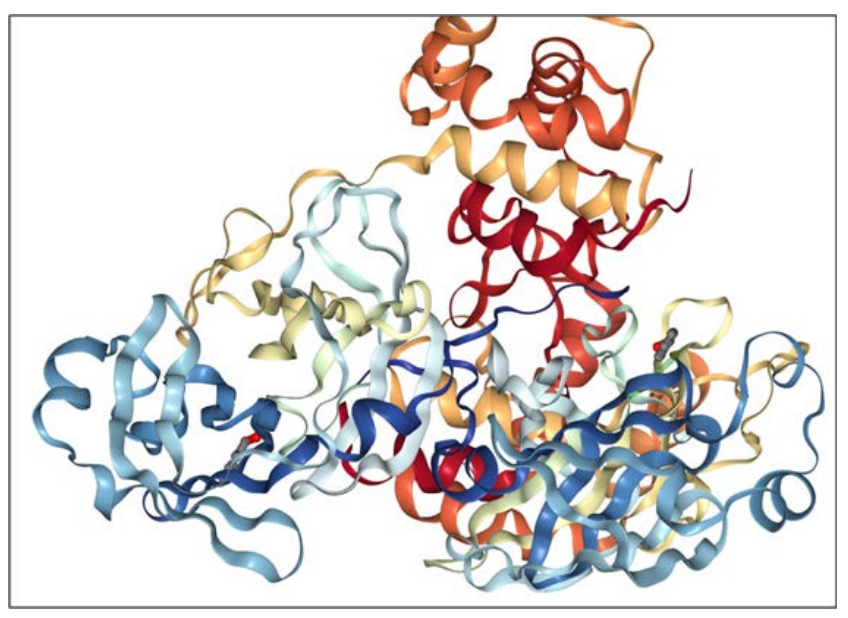

Figure 2. The 3D crystal structure of SARS-CoV-2 protease (PDB ID: 6LU7).

Meanwhile this protease has its crystal structure in a state that signifies the pharmacological target for the progress of new medicines to treatment diverse infectious diseases. The preparation of the target enzyme 6LU7 with the Auto-Dock tools software intricate addition of all $\mathrm{H}_{2}$ atoms to the enzyme, which is a step essential for accurate calculation of fractional atomic charges. The ligand and all water molecules were detached to make the structure for docking. Gasteiger charges are considered for each atom of the protein in AutoDock 4.2 instead of Kollman charges which were used in the earlier versions of this package.

\subsection{Docking Procedure}

For ligand conformational incisive, we take the 'Lamarckian-Genetic Algorithm (LGA)', which is a mixture of a genetic algorithm and a native search algorithm. This algorithm initially builds a population of entities, being a diverse casual conformation of the docked enzyme. Each distinct protein is then mutated to attain a slightly diverse translation and alternation and the local search algorithm then achieves energy minimizations on a user-specified amount of the population of individuals. The entities with the low subsequent energy are moved to the succeeding generation and the procedure is then repetitive. This algorithm is called Lamarckian while every novel group of entities is allowable to receive the local search variations of their parents.

To get many docked structures, Auto-Dock was run numerous times, and used to examine the expected docking energy. Rapid energy assessment was attained by pre-calculating nuclear affinity capacities for every atom in the compound molecule. The binding sites of the target enzyme for these molecules in the Auto Grid process were designated on the patterns of founded ligand-binding pockets $^{12}$. Auto-Dock Tools deliver various approaches to examine the outcomes of docking-simulations such as, structural resemblance, and other limitations like intermolecular energy, visualizing the binding site and its energy and inhibition constant. The energy of interaction of every atom in the ligand was met. For each ligand, 10 best postures were made and scored using Auto-Dock 4.2 scoring purposes ${ }^{13}$.

\section{Results and Discussion}

\subsection{Computational Prediction of Anti-Viral Activity}

For three selected FDA accepted drug molecules PASS calculation of anti-viral activity was achieved. Calculation was conceded out by means of PASS online ${ }^{14}$ version. The anti-viral activity was calculated for all particular compounds, with $\mathrm{Pa}$ values in range of $0.323-0.602$ (Table 1). The predicted Pa values for the most of selected composites were less than 0.5 , representing their virtual novelty compared to the structures of the drugs from the PASS training set ${ }^{15,16}$. All the three compounds $\mathrm{Pa}$ values are higher (lopinavir 0.538; ritonavir 0.602; Hydroxychloroquine 0.623 ). However, the computational prediction of anti-viral activity results states that, the compounds exhibiting anti-viral effect.

\subsection{Molecular Docking Prediction}

Binding energy is the preliminary parameter which is generated as a consequence of molecular docking. It gives us the knowledge of strength and attraction of the interaction between the ligand and the target enzyme. The higher the binding energy is, the frailer the interaction is and vice versa. Therefore during any docking study, we propose to look for the ligand which shows the minimum binding energy, thus the best attraction amongst the test molecules. Among the test compounds in this study, hydroxychloroquine displayed the lowermost binding energy of $-8.30 \mathrm{Kcal} / \mathrm{Mol}$. The binding energy of the lopinavir and ritonavir was higher $(-6.11 \&-8.25)$ than the hydroxychloroquine. The binding energies of the tested compounds have been showed in Figure 3 and Table 1. 
Table 1. Molecular docking parameters and PASS calculation of the selected ligands

\begin{tabular}{|c|c|c|c|c|c|c|}
\hline Sl. No. & $\begin{array}{l}\text { Compound } \\
\text { Name }\end{array}$ & $\begin{array}{c}\text { Predicted } \\
\text { Anti-viral } \\
\text { Efficacy }(\mathbf{P a})\end{array}$ & $\begin{array}{c}\text { Binding } \\
\text { energy } \\
\text { (Kcal/ Mol) }\end{array}$ & Residue involving interaction & $\begin{array}{l}\text { No. } \\
\text { of } \mathrm{H} \\
\text { bonds }\end{array}$ & $\begin{array}{l}\text { Interac-tion } \\
\text { of residues } \\
\text { forming } \mathrm{H}_{2} \\
\quad \text { bonds }\end{array}$ \\
\hline 1. & Lopinavir & 0.538 & -6.11 & $\begin{array}{l}\text { GLU:166, ASN:142, SER:144, HIS:163,164 } \\
\text { PHE:140, CYS:145, LEU:141,167 ARG:188, } \\
\text { MET:165, GLN:189,192, ALA:191, THR:190 }\end{array}$ & 1 & GLU:166 \\
\hline 2. & Ritonavir & 0.602 & -8.25 & $\begin{array}{c}\text { GLY:143,170, GLU:166, LEU:141,27,167, } \\
\text { PHE:140, CYS:145, ASN:142, HIS:41, } \\
\text { ASP:187, MET:49,163 ARG:188, } \\
\text { GLN:189,192, THR:190, ALA:191, GLY:170, } \\
\text { PRO:168, }\end{array}$ & 1 & GLY:143 \\
\hline 3. & $\begin{array}{l}\text { Hydroxy- } \\
\text { chloroquine }\end{array}$ & 0.623 & -8.30 & $\begin{array}{l}\text { GLN:189, ARG:188, MET:165, TYR:54, } \\
\text { ASP:187, HIS:41,172,163,164, PHE:140, } \\
\text { LEU:141, CYS:145, SER:144, ASN:142, } \\
\text { GLY:143, GLU:166 }\end{array}$ & 1 & GLN:189 \\
\hline
\end{tabular}

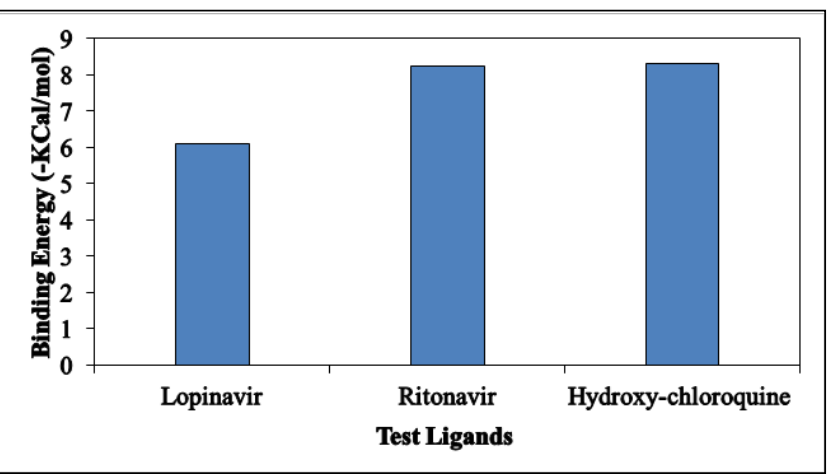

Figure 3. Binding energy values of the test ligands.

Using the same parameters, FDA approved two retroviral drugs and one anti-malarial drug were docked to the 'SARS-CoV-2 protease' (PDB ID: 6LU7) enzyme (Table 1). All tested compounds showed very worthy binding scores and taking into explanation moreover the calculation results by PASS. Anti-malarial drug, hydroxychloroquine shows higher binding energy values than the other compounds.

The amino acids of SARS-CoV-2 virus involved in the interaction with test compound lopinavir are GLU:166, ASN:142, SER:144, HIS:163,164 PHE:140, CYS:145, LEU:141,167 ARG:188, MET:165, GLN:189,192, ALA:191, THR:190 (Figure 4\&5). The interaction of these amino acids states that, the inhibition of SARSCoV-2 protease with lopinavir with one hydrogen bond formation.

GLY:143,170, GLU:166, LEU:141,27,167, PHE:140, CYS:145, ASN:142, HIS:41, ASP:187, MET:49,163

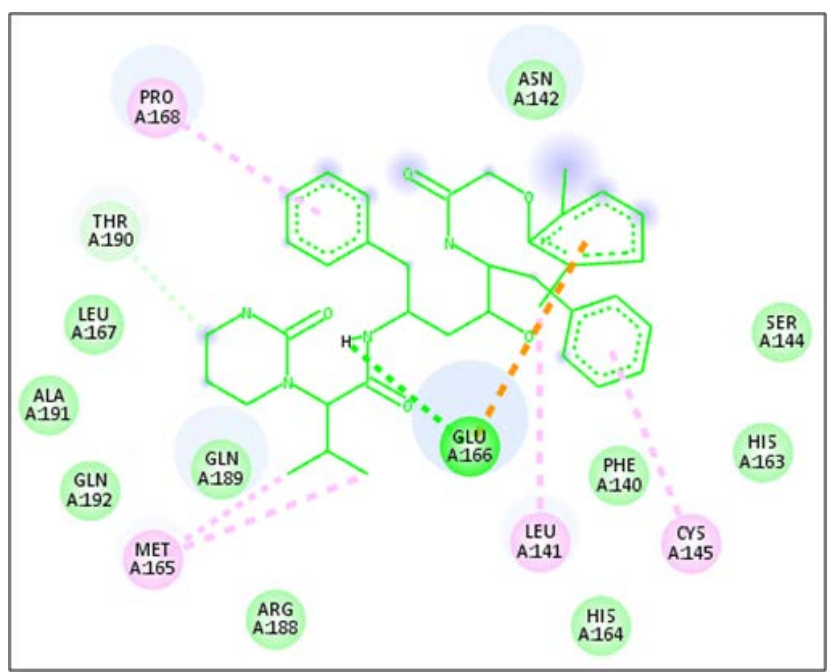

Figure 4. Docking lopinavir with SARS-CoV-2 protease (2D Diagram).

ARG: 188, GLN:189,192, THR:190, ALA:191, GLY:170, PRO:168 are the amino acids involved in the interaction with ritonavir (Figure 6\&7) with binding energy -8.25 $\mathrm{kcal} / \mathrm{mol}$.

The nitrogen atom of $\mathrm{Gln} 189$ binds with the $\mathrm{O}_{2}$ atom of the hydroxychloroquine establishing a $\mathrm{H}_{2}$ bond. The other ring interrelates hydrophobically through the amino acid moieties Gln:189, Arg:188, Met:165, Tyr:54, Asp:187, His:41,172,163,164, Phe:140, Leu:141, Cys:145, Ser:144, Asn:142, Gly:143, Glu:166. These hydrophobic interactions donate expressively to the maintenance of the compound-SARS-CoV-2 protease enzyme complex. 


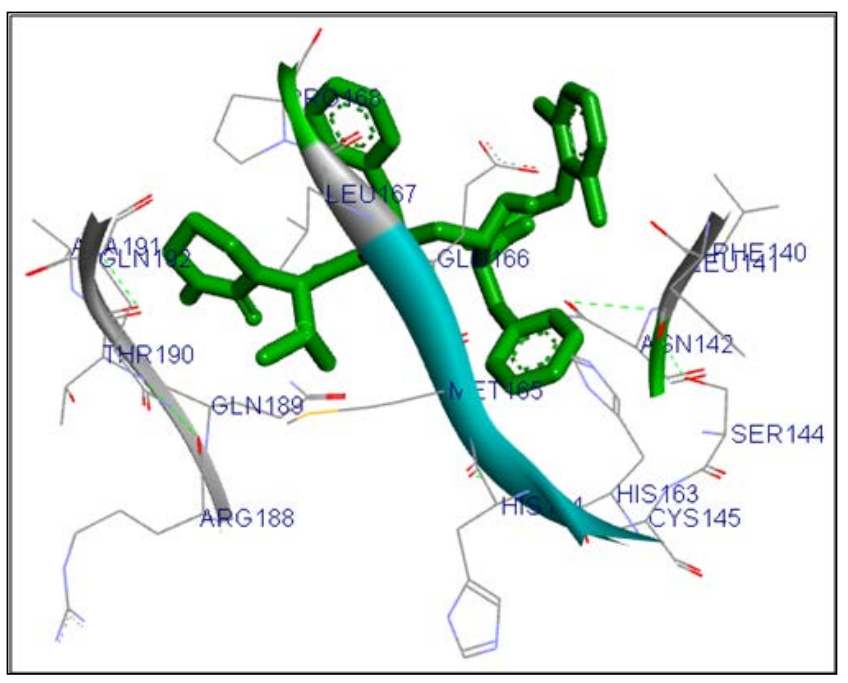

Figure 5. Docking lopinavir with SARS-CoV-2 protease (3D Diagram).

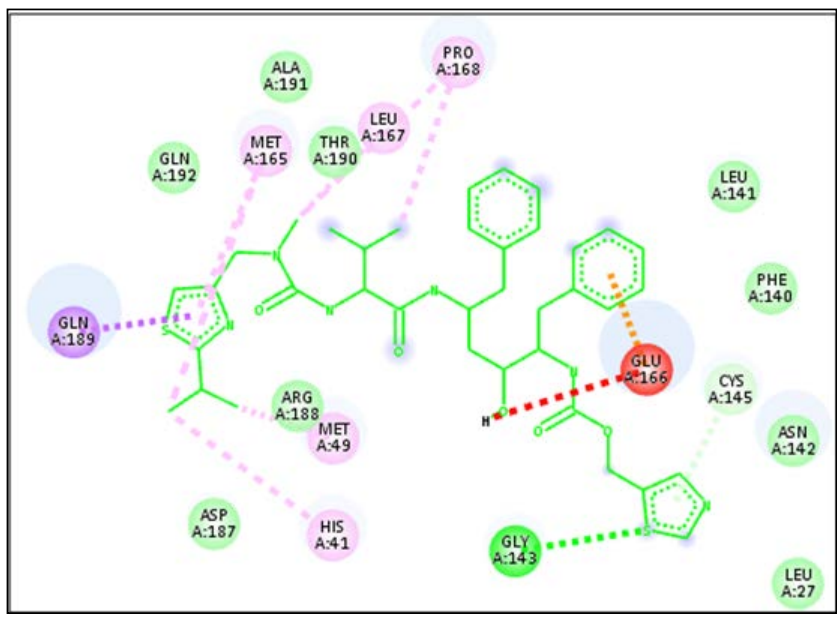

Figure 6. Docking ritonavir with SARS-CoV-2 protease (2D Diagram).

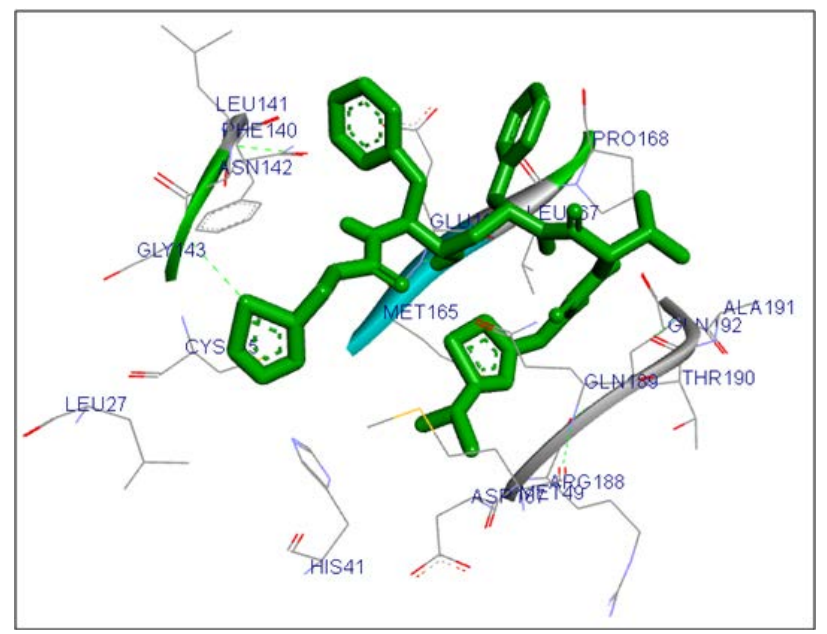

Figure 7. Docking ritonavir with SARS-CoV-2 protease (3D Diagram).
As shown in Figure 8 and 9, the hydroxychloroquine ring is positioned exclusive the cavity bounded by the amino acid residues Met165, Cys145, His172, and His163. It is significant to reference that the occurrence of the $\mathrm{H}_{2}$ bond with Gln189 is typical of various anti-viral inhibitors.

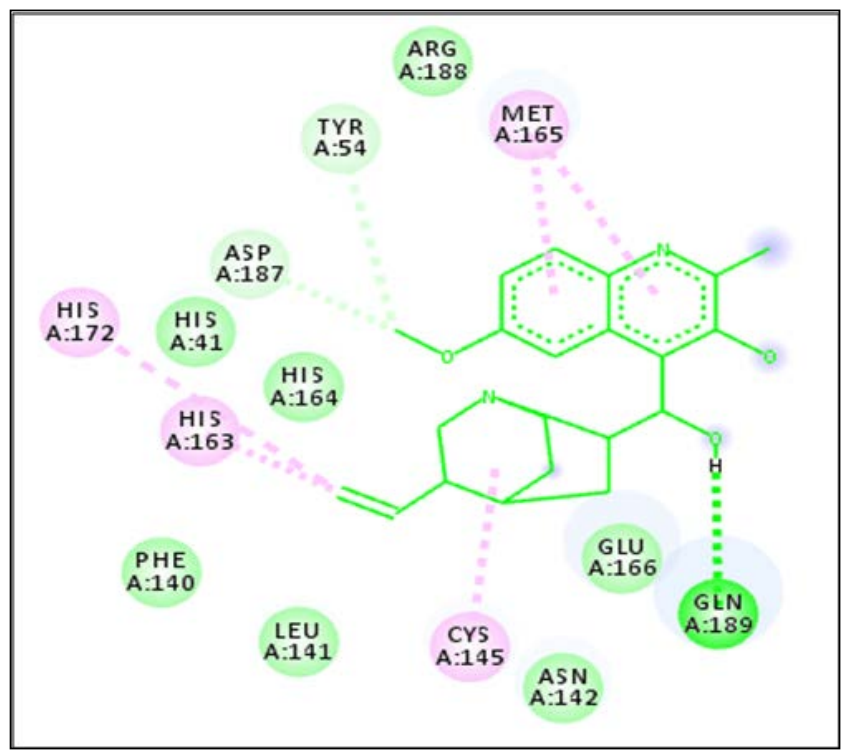

Figure 8. Docking hydroxychloroquine with SARS-CoV-2 protease (2D Diagram).

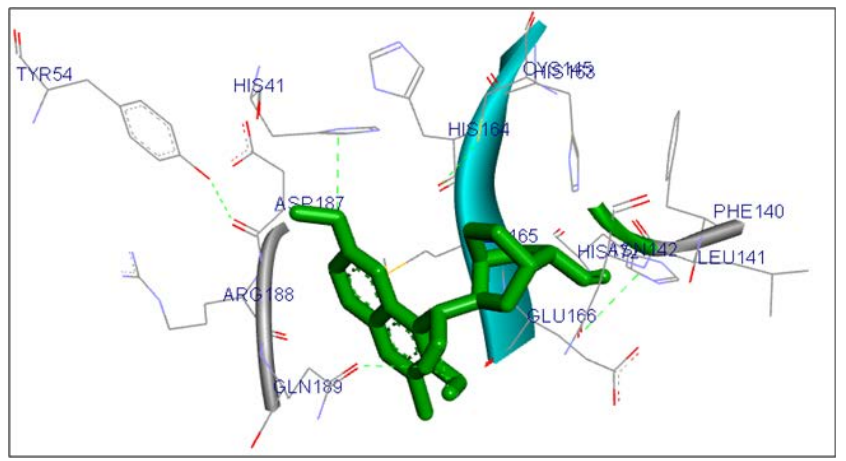

Figure 9. Docking hydroxychloroquine with SARS-CoV-2 protease (2D Diagram).

Outcomes from the In Silico molecular docking study maintained the great inhibitory efficacy of the two retroviral drugs and one anti-malarial compound since they could launch $\mathrm{H}_{2}$ bonds with Glu166, Gly143, and Gln189, the residues of amino acids contributing in the 30-processing response. They also binds with the amino acid residues Lys159, Glu152, Gln148, and Asn 155 involved in the strand transmission reaction ${ }^{17}$ that caused in an inhibition of SARS-CoV-2 protease activity. Thus, the projected binding interactions of the dynamic molecules with the protease by the docking study evidently established their inhibitory strength towards catalytic response of the protease. 


\section{Conclusion}

The present study concludes that, two retroviral drugs and one anti-malarial drug showed efficient docking score. These outcomes afford a strong foundation for the use of hydroxychloroquine, lopinavir and ritonavir for CORONA management. Moreover, the dynamic ligands inhibited the catalytic response of protease by blocking the residues of amino acids intricate in the processing and strand transmission reactions. The interactions by the structural model at the protease active site can afford a valuable guide for additional strategies for structurebased medicines and development of new operative inhibitors of SARS-CoV-2 protease.

\section{Acknowledgement}

All the authors are gratefully acknowledged to Department of Zoology, Kakatiya University, Warangal, Telangana, India for providing Bioinformatics lab to carry out this study. No funding to declare.

\section{References}

1. Zhou P, Yang X-L, Wang X-G, Hu B, Zhang L, Zhang W, Si H-R, Zhu Y, Li B, Huang C-L, Chen H-D, Chen J, Luo Y, Guo H, Jiang R-D, Liu M-Q, Chen Y, Shen X-R, Wang X, Zheng X-S, Zhao K, Chen Q-J, Deng F, Liu L-L, Yan B, Zhan F-X, Wang Y-Y, Xiao G-F, Shi Z-L. A pneumonia outbreak associated with a new corona virus of probable bat origin. Nature. 2020; 579:270-73. https://doi.org/10.1038/s41586020-2012-7. PMid: 32015507, PMCid: PMC7095418.

2. Wu F, Zhao S, Yu B, Chen Y-M, Wang W, Song Z-G, Hu Y, Tao Z-W, Tian J-H, Pei Y-Y, Yuan M-L, Zhang Y-L, Dai F-H, Liu Y, Wang Q-M, Zheng J-J, Xu L, Holmes EC, Zhang Y-Z. A new corona virus associated with human respiratory disease in China. Nature. 2020; 579:265-69. https://doi. org/10.1038/s41586-020-2008-3. PMid: 32015508, PMCid: PMC7094943.

3. World Health Organization. Pneumonia, 2020 of unknown cause - China. Available from: https://www.who.int/csr/ don/05-january-2020-pneumonia-of-unkown-causechina/en/.

4. Giovanetti M, Benvenuto D, Angeletti S, Ciccozzi M. The first two cases of 2019-nCoV in Italy: Where they come from? J. Med. Virol. 2020. PMID: 32022275. https:// doi.org/10.1002/jmv.25699. PMid: 32022275, PMCid: PMC7166327.
5. Shigemura J, Ursano RJ, Morganstein JC, Kurosawa M, Benedek DM. Public responses to the novel 2019-coronavirus (2019-nCoV) in Japan: Mental health consequences and target populations. Psychiatry Clin. Neurosci. 2020. PMID: 32034840. https://doi.org/10.1111/ pcn.12988. PMid: 32034840, PMCid: PMC7168047.

6. WHO Severe Acute Respiratory Syndrome (SARS) Weekly. Epidemiol. Rep. 2020; 78:86.

7. Indian Council of Medical Research (ICMR), Government of India. COVID-19 cases. Available online: https://www. icmr.nic.in/content/covid-19.

8. Anand K, Ziebuhr J, Wadhwani P, Mesters JR, Hilgenfeld R. Corona virus main proteinase (3CLpro) structure: Basis for design of anti-SARS drugs. Science. 2003; 300:1763-67. https://doi.org/10.1126/science.1085658. PMid: 12746549.

9. Nadaraia NS, Amiranashvili LS, Merlani M, Kakhabrishvili ML, Barbakadze NN, Geronikaki A, Petrou A, Poroikov V, Ciric A, Glamoclija J, et al. Novel antimicrobial agents' discovery among the steroid derivatives. Steroids. 2019; 144:52-65. https://doi.org/10.1016/j.steroids.2019.02.012. PMid: 30776376.

10. Kouatly O, Eleftheriou P, Petrou A, Hadjipavlou-Litina D, Geronikaki A.Docking assisted design ofnnovel4-adamantanyl2-thiazolylimino-5-arylidene-4-thiazolidinones as potent NSAIDs. SAR QSAR Environ. Res. 2018; 29:83-101. https://doi. org/10.1080/1062936X.2017.1410220. PMid: 29299942.

11. https://www.rcsb.org/structure/6LU7. Accessed on 23 March 2020.

12. Chang MW, Ayeni C, Breuer S. Virtual screening for HIV protease inhibitors: A comparison of AutoDock 4 and vina. PLoS ONE. 2010; 5:119-55. https://doi.org/10.1371/journal. pone.0011955. PMid: 20694138, PMCid: PMC2915912.

13. Park H, Lee J, Lee S. Critical assessment of the automated AutoDock as a new docking tool for virtual screening. Proteins. 2006; 65:549-54. https://doi.org/10.1002/ prot.21183. PMid: 16988956.

14. Filimonov DA, Lagunin AA, Gloriozova TA, Rudik AV, Druzhilovskiy DS, Pogodin PV, Poroikov VV. Prediction of the biological activity spectra of organic compounds using the PASS online web resource. Chem. Heterocycl. Compd. 2014; 50:444-57. https://doi.org/10.1007/s10593014-1496-1.

15. Geronikaki A, Dearden JC, Filimonov D, Galaeva I, Garibova TL, Gloriozova T, Kraineva V, Lagunin A, Macaev FZ, Molodavkin G, et al. Design of new cognition enhancers: From computer prediction to synthesis and biological evaluation. J. Med. Chem. 2004; 47:2870-76. https://doi.org/10.1021/jm031086k. PMid: 15139765.

16. Geronikaki A, Babaev E, Dearden J, Dehaen W, Filimonov D, Galaeva I, Kraineva V, Lagunin A, Macaev F, Molodavkin, G, et al. Design, synthesis, computational and biological evaluation 
of new anxiolytics. Bioorg. Med. Chem. 2004; 12:6559-68. https://doi.org/10.1016/j.bmc.2004.09.016. PMid: 15556772.

17. Dayam R, Neamati N. Active site binding modes of the beta-diketoacids: A multi-active site approach in HIV-1 integrase inhibitor design. Bioorg. Med. Chem. 2004; 12:637181. https://doi.org/10.1016/j.bmc.2004.09.035. PMid: 15556755. 